\title{
NURSING RESEARCH: A WORLDWIDE PICTURE
}

Mo Im Kim*

\section{Introduction}

Nursing research is not only a tool that professional nurses and nurse scholars use to obtain the knowledge and information needed to make daily practice and administrative decisions but also a tool to prove value of nursing to the society. Without research, there will be no growth of nursing or advancement of nursing as a profession. And only when we can prove that nursing is capable of generating knowledge befitting the future society, can nursing remain a viable profession and a respectable academic discipline in coming 21 st century.

I am confident that throught nursing research, we nurses can and will prove cost-effectiveness and contribution of nursing to health of people. And we will lead the way to findindg cost-effective alternatives to present medical care system heavily centered around the expensive hospital care. Let us invest in nursing research. To invest in research is to invest for a better future.

\section{Study Method}

Descriptive study is the type of research analyzing existing data in depth. It was almost impossible to conduct a study to a world view on nursing due to time constrains. To describe about a wolrdwide picture of nursinf research, was not easy due to the lack of literatures and limited acessibility. Fortunately ICN undertook two good projects in relation to Nursing Research.

One of ICN's priorities for 1988-93 was "nursing research" aimed at "more effective participation in health policy making and health care delivery through cooperation with nacional nurses associations and nurses to encourage and facilitate the development of research in nursing and the dissemination of research findings".

With this objective in mind 1) an updated version of the "Directory on Nursing Research Units" was released in 1990, incorporation data in effect as of 1988.

The term "Nursing Research Unit" means any departmental set-up,

- RN, Dr. P.H., Dean \& Professor College of Nursing, Yonsei University. 
group, or structure formed for the purpose of carrying out or expediting nursing research. The directory was published in order "to facilitate and promote communication and collaboration among nurse researches both nationally and internationally".

In late spring of 1990,2) a group of nurse scholars met as members o the Task Force on Nursing Research at the headquarters of the International Council of Nurses in Geneva, Switzerland.

Their meeting was sponsored jointly by the ICN, the Center for Nursing Research, and the National Institute of Health of the United States.

The participants represented six regions of the world: North America, South/Central America \& the Caribbean, Europe, Africa, the Western Pacific, and Southeast Asia.

The two principal resource materials used for this paper were the "Directory of Nursing Research Unit" and "Nursing Research Worldwide", a Task Force on Nursing Research report.

\section{Limitation os Study}

ICN devides its member nations into 7 regions, against which the countries referred to in this research have been examined.

$<$ Table $1>$ shows the number and ratio of ICN members by regions. This; table indicates that the ratio of countries falling into the North American region was $100 \%$ whereas that of nations belonging to the other 6 regions ranged from $5.0 \%$ to $41.7 \%$.

In this paper a total of 22 coutries representing the 7 regions have been studied; twenty of them, here analyzed in accord with the data in the "Directory of Nursing Research", represent 5 regions, while 9 of them, here examined against the data in "Nursing Research Worldwide", represent 6 regions.

One of the drawbacks of this study is two-fold: (1) the insufficiency of data and (2) the question of representation with respect to the countries examined vis-a-vis the regions to which they belong.

\section{Study Findings}

1) A world picture Nursing Research based upon Directory of Nursing Research Unit can be identified as follows (See Table 2-5).

(1) The total number of nursing research units: There are 114 nursing research units in the world.

\begin{tabular}{|c|c|c|}
\hline $\begin{array}{l}61 \text { units } \\
27 \\
12 \\
8\end{array}$ & $\begin{array}{l}(53.5 \%) \text { in } \\
(23.7 \%) \\
(10.5 \%) \\
(7.0) \% \\
(5.3 \%)\end{array}$ & $\begin{array}{l}\text { North America } \\
\text { Europe } \\
\text { South/Central A } \\
\text { Eastern Mediter }\end{array}$ \\
\hline
\end{tabular}

(2) Type of setting: Schools or colleges of nursing functioning as part 
of a university, a health center or a medical center constituted $37.7 \%$ of all research institute units, followed by $19.3 \%$ and $10.5 \%$ representing those operating as part of a university and a hospital respectively.

Regionally, the most prevalent type (3) is characteristic of North America and other regions except Europe, where the prevailing type of setting is one associated with universities; the "hospital type" is found in various regions including North America, Europe, South/Central America and the Caribbean area.

(3) Disciplines included: Globally, a distinct trait of the academic make-up of nursing research units was interdisciplinary, for research centers having institutional ties with other disciplines represented $66.7 \%$ and regionally were found largely in North America, Europe, and Eastern Mediterranean. Nursing was associated with 21 other disciplines including medicine, education, psychology, and sociology among others.

(4) Research Center Activities: Most research centers were engaged both in research per se and providing support for such rather than carrying out one kind of activity only - a trend deemed regional 1 as well.

(5) Size of professional staff: On the average a research center had a staff of 4 to 6 at most, certainly a modest size found to be true of all regions.

(6) Support activities: The content matter of support activities performed by research units comprised research design consultation (75.4\%), information about funding opportunities (71.9\%), instrument/questionaire development (62.3\%), statistical/biostatistical consultation (58.8\%), and so forth.

(7) Besearch DesigniThe most widely used research design was of the experimental/quasi-experimental sort (71.9\%) favored predominantly followed by surveys (71.1\%) and phenomenological/qualitative designs (48.2\%).

(8) Characteristics of nursing research: The aim focus of attention in research was recipients of nursing care $\mathbf{7 7 . 8 \%}$ ), followed by nursing practice $(\mathbf{7 1 . 9 \%})$, nurses $(57.8 \%)$, research methodology $(56.1 \%)$, nursing theory (51.8\%), nursing education $(51.8 \%)$, and organization management and administration (35.1\%).

To be more specific, researches on recipients of nursing care highlighted adult men and/or women $(64.0 \%)$ while those concerned with nursing practice covered mostly the effectiveness of nursing interventions (56.1\%).

Studies on nurses were about knowledge, attitudes, skills, and practices by nurses while the primary object of studies on research methodology was the development and testing of measurement tools.

Regionally, researches conducted in North America, Europe, South/Central America and the Caribbean were chiefly concerned 
with recipients of nursing care whereas studies in the Western Pacific area dwelled mainly on recipients of nursing care, nursing theory, nurses, and organization management and administration; researches in the Eastern Mediterranean showed a lot of interest in nursing education.

A majority of researches carried in North America were about adult men and women while studies on nursing practice highlighted the effectiveness of nursing interventions. Similar trends were also discovered in Europe. In the Western Pacific Region studies on nursing care recipients were greatly concerned with elderly men and/or women while many of the studies on nursing theory and the development and testing of measurement.

Studies on nurses were largely about knowledge, attitudes, skills, and practice while those on nursing management and administration were concerned with working conditions and risk factors for nurses.

In South/Central America and the Caribbean the focus was on adolescents. Whereas the prevalent subject of researches on nurising practice was quality of care.

In Eastern Mediterranean the dominant subjects of researches on nursing education were the attitudes of nursing and their knowledge and skills; studies of nurses were mainly about infants and children while those on nurses highlightes knowledge, attitudes, and skills.

Next is a worldwide picture of nursing research based on task force on nursing research. The participants came from nine different countries, representing six regions of the world and they reported varying levels of progress and sophistication in nursing research.

What follows are summaries of reports field by representatives of participating countries:

\section{North America}

- Dr. J. S. Norbeck, U.S.A.: Following the establishment of the National Center for Nursing Research, the United States marked a shift in attention from scholar development to knowledge development; priorities of NIH funding for nursing research were symptom management (29\%), health promotion (12\%), long-term care (12\%) and others.

At a recent conference on nursing research held in Washington, D. C., in August, this year the director of NIH announced that the NCNR would be upgraded to National Institute of Nursing Research in very near future.

- L. F. Degner, Canada: According to the study by Stinson and others in 1990, most studies to date were clinical problems rather than Nursing Education and Administration - a trend reflecting the specialization in 1 nursing that began after 1965 . Nursing research became especially active 
in Canada with the appointment of nurses on the Medical Research Council in 1986; today quite a few nurses serve on the Medical Research Council Peer Review panels, taking part in decision making and business deliberations.

\section{South/Central America \& Caribbean}

- Dr. Tamara I. Cianciarullo, Brazil reported that her analyses of master's theses and doctoral dissertation topics, conducted jointly with Nogueira (1982) at Woman's Self Care Center (1990), showed changes in attention from nursing education in the 1950's to nursing profession and nursing methodology through the 1960 's-70's to patient need in the 1980's.

Europe

According to Dr. E. K. F. Hamrin, Sweden, significant growth in nursing research occured following educational developments, especially with a new law introduced on january 1, 1983 to honor the rights of patients.

Doctoral dissertation are concerned with clinical practice as exemplified by topics on elderly care, communication/information in clinical practice, etc.

- A. J. Tierney, U. K. made a comment that research programs pursued by British nursing research units emphasize practice - relevant studies. Research work is being actively promoted by funding and manpower rendered/by activities of a Chief Nursing officer who serves on the Health Boards of the National Helath Service.

Africa

- Dr. R. A. Olade, Nigeria reported that findings by Filani (1988) indicate nursing research is still in the begginning stage as attested by the fact only 24\% of articles published in Nigerian Nurse between 1975 and 1984 were: research-based the remainder being case studies.

\section{Western Pacific}

- Dr. E. S. Kim, Korea reported that nursing research of the WHO Collaborating Center Yonsei University College of Nursing conducted a study for the purpose of establishing the Nursing Resource Data Bank in 1989. The data show that, of Korea's 573 nurse educators, 394 reported they had research articles published over the past five years.

An analyses of their topics show that the major concepts tackled were stress and anxiety, health bahavoir and compliance, nursing activity, and perception - concepts having to do with clinical research rather than nursing education or nursing administration.

According to Y. Higuchi, Japan: Researches to date have dwelled on 
clinical studies measuring the effectiveness of nursing and nursing techniques, model/concept development, nursing education, and nursing administration.

\section{South/East Asia}

- Dr. T. Boontong, Thailand reported that reviews of nursing studies made by the Divison of Nursing Colleges and Ministry of Public Health up to 1989 suggest that $59.9 \%$ of them were about nursing practice, $32.0 \%$ on nursing aducation, and $11.9 \%$ about nursing administration.

\section{Conclusion}

A worldwide pictures form two different resource indicate that nursing research in all regions except North America needs a great deal of investment and effort if it is to progress from the scholar development stage to the knowledge development stage.

And I honestly believe in that advances in nursing research worldwide would be realized also when and if we can meet the kinds of need noted by the ICN Task Force for Nursing Research, let me enumerate the needs for you;

1) First and foremost, professional consciousness raising of the need for nursing research and for an educational system that provides respectable and efficient pathways to scholarly pursuit and research opportunities.

2) A need to set high standard within master's and doctoral programs which are critical to the advancement of research. These would include, for example, qualified facuity, appropriciate objectives at different levels of preparation, and faculty involvement in research programs.

It is common knowledge that one of the three major funtions of any academic institution is research, which is possible only when you have well-trained scholars who usually receive their trainig from a graduate school.

An institution of higher learning not only provides education but also generates knowledge through research, and that is why the university normally has graduate schools providing us with research personnel and training students to develop research skills.

For example <Table $6>$ lists figures on individuals doing graduate work for master's and doctoral degrees and $\mathrm{Ph}$. D. degree holders.

Data on holders of doctoral degrees were not sufficient enough to draw a regional overview.

For this reason, only a limited observation follows on five contries: The United States tops other nations by a great margin in terms of master's and doctoral degree courses. Although Thailand is ahead of the U. S., Korea, Canada, and Japan in that order with respect to the percentage of nurses with $\mathrm{Ph}$. $\mathrm{D}$. degrees relative to the number of nurses, the sheer number of doctors of nursing in the U. S. is so great 
that the figures of other countries pale before hers. And the difference has significant implications.

Thus one might conclude that North America has really advanced to the information generating (knowledge development) stage while other regions are still at the stage scholar (nurse/researcher) development.

3) The need to disseminate nursing research findings to various sectors of the public.

4) Within countries, as education and research capabilities evolve, needs, will emerge and occur on a continuum, including the need to:

secure basic research resources such as access to journals, library facilities, data bases, etc;

develop nursing research centers.in order to stimulate the kinds of activities that make progress happen;

develop a stable national funding base;

articulate national research priorities that will challenge the researches to respond to needs for knowledge development;

create mechanisms to sustain research careers;

create centers of excellence;

develop mechanisms to disseminate with the vast output that occurs in countries where research is very well established.

As we enter the last decade of this century, we must seriously examine the unfinished agenda of nursing research. For, as you know the 21st century is not a mere extension of today but a stage where countries changes unfold, perhaps necessitating research that we had not ever imagined. The futurists say that 21 st century will be a society of information, globalization and supra industrialization.

If that is the case, the discipline of nursing must change so it can absorb the impacts which are likely to come with such phenomena. And if that's the case, we might as well undergo changes in an active rather than passive manner. The changes we undertake, then, will have to be based on sound research.

Let me remind you of that we are entering into a society. We must prove nursing can make substantial contributions to the health of people both in terms of economic efficiency and the role of nursing in improving health care. 


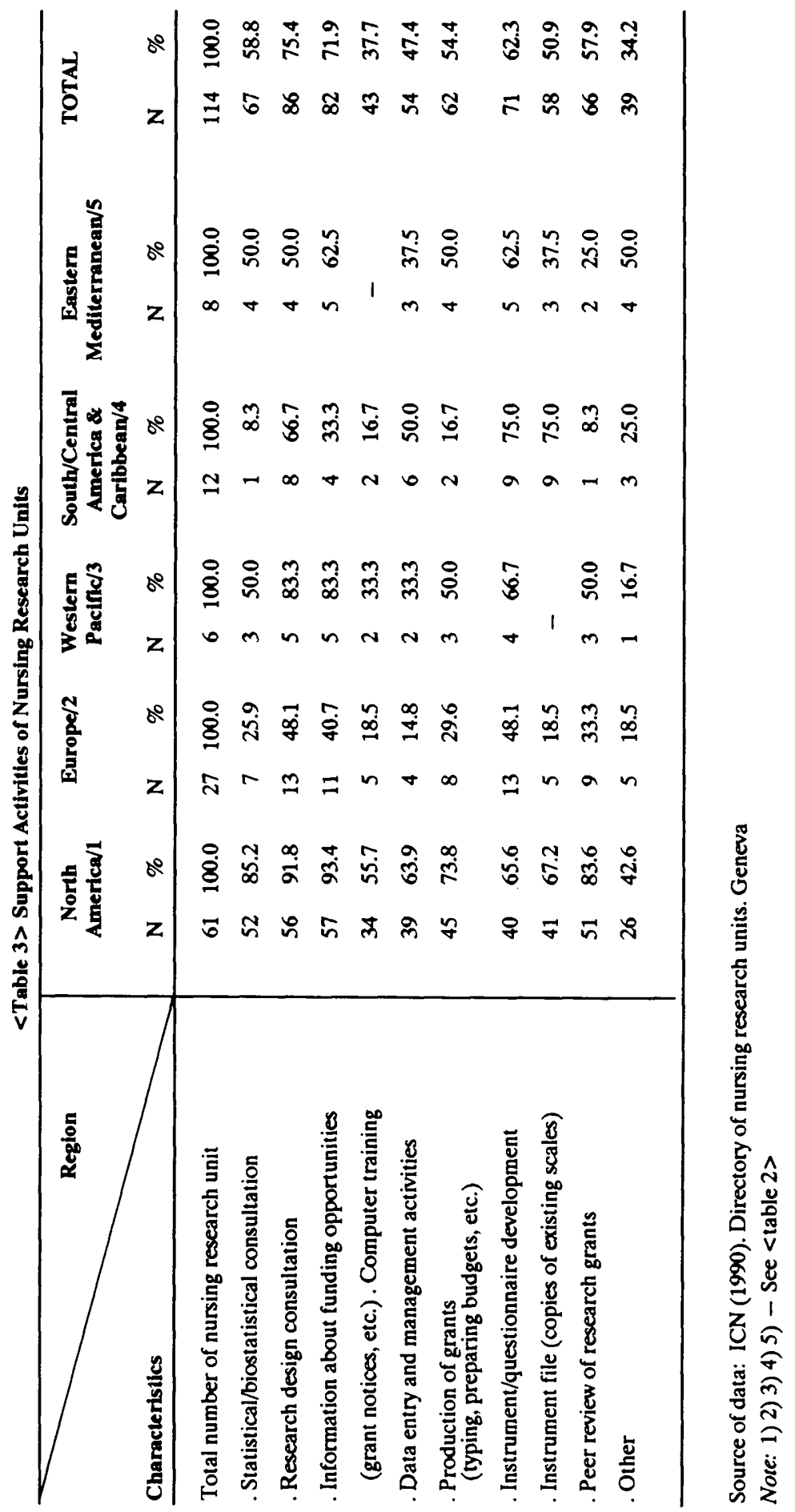




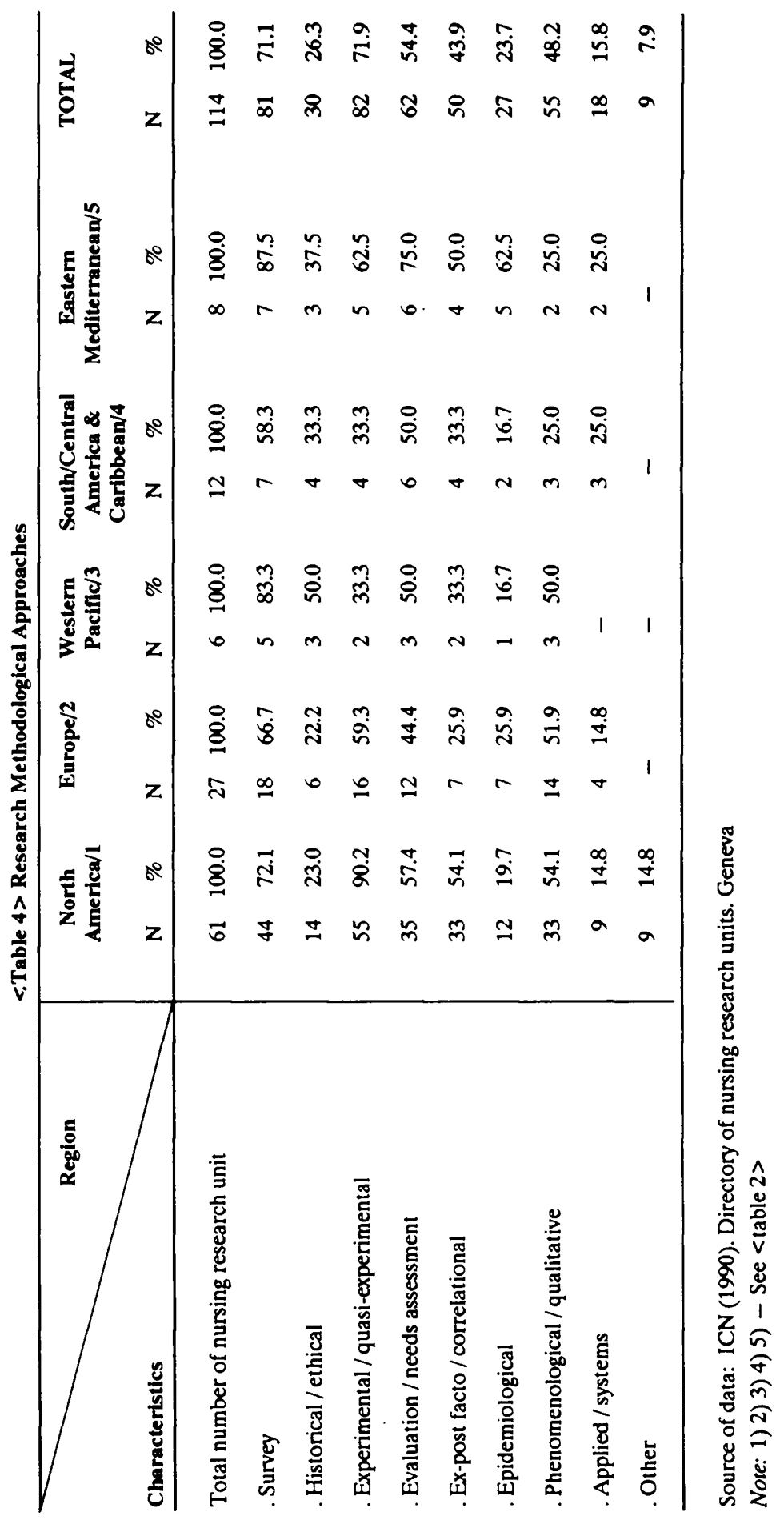




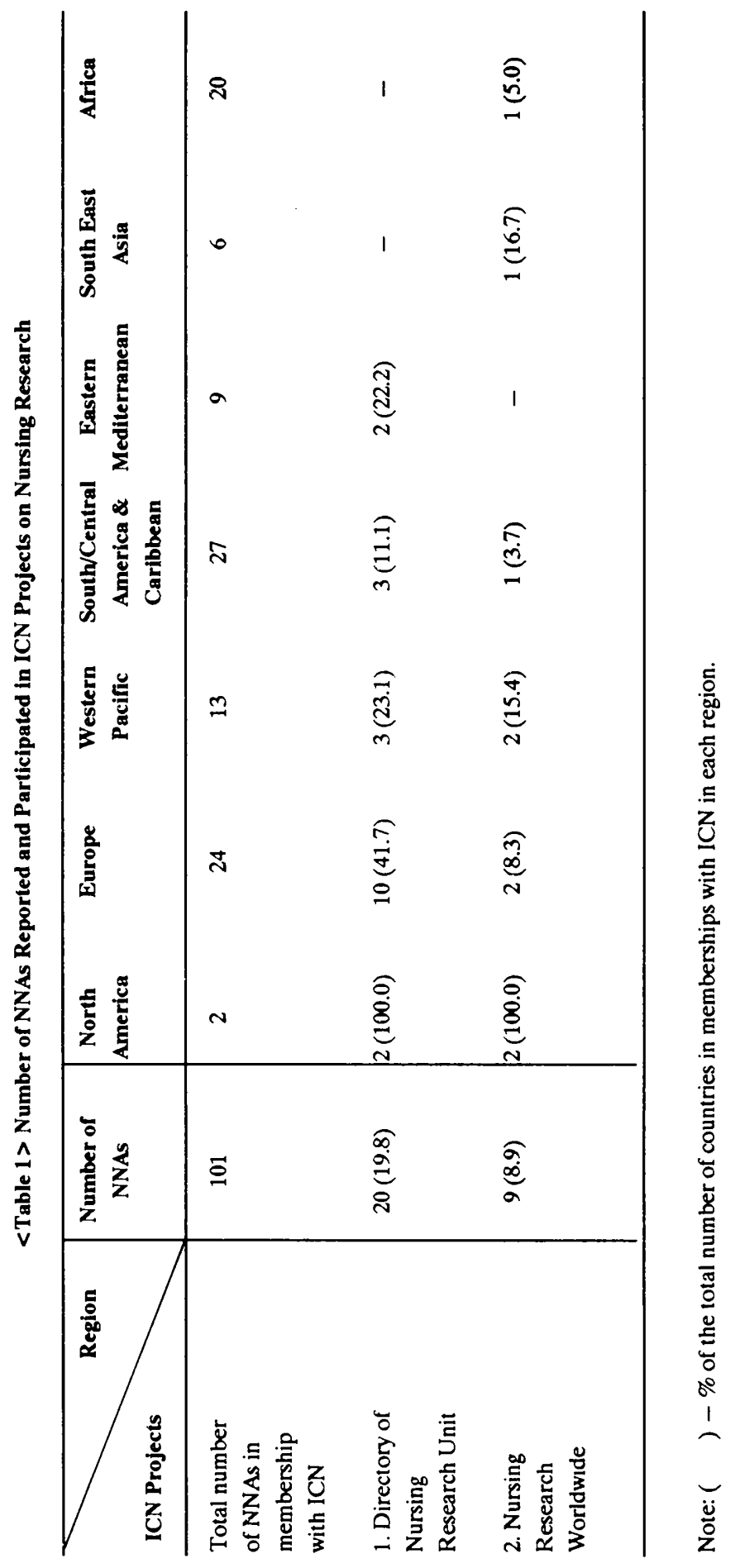




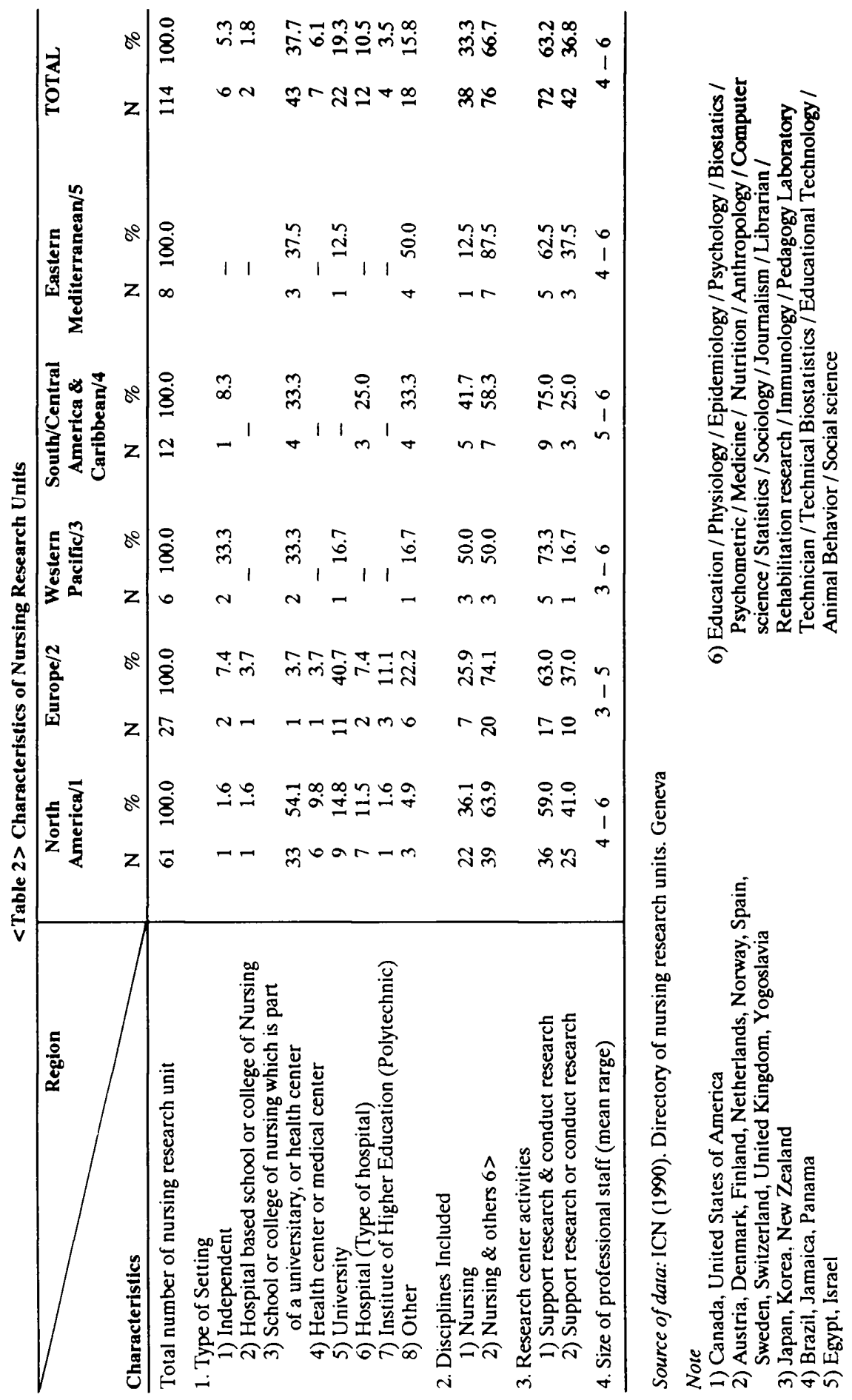




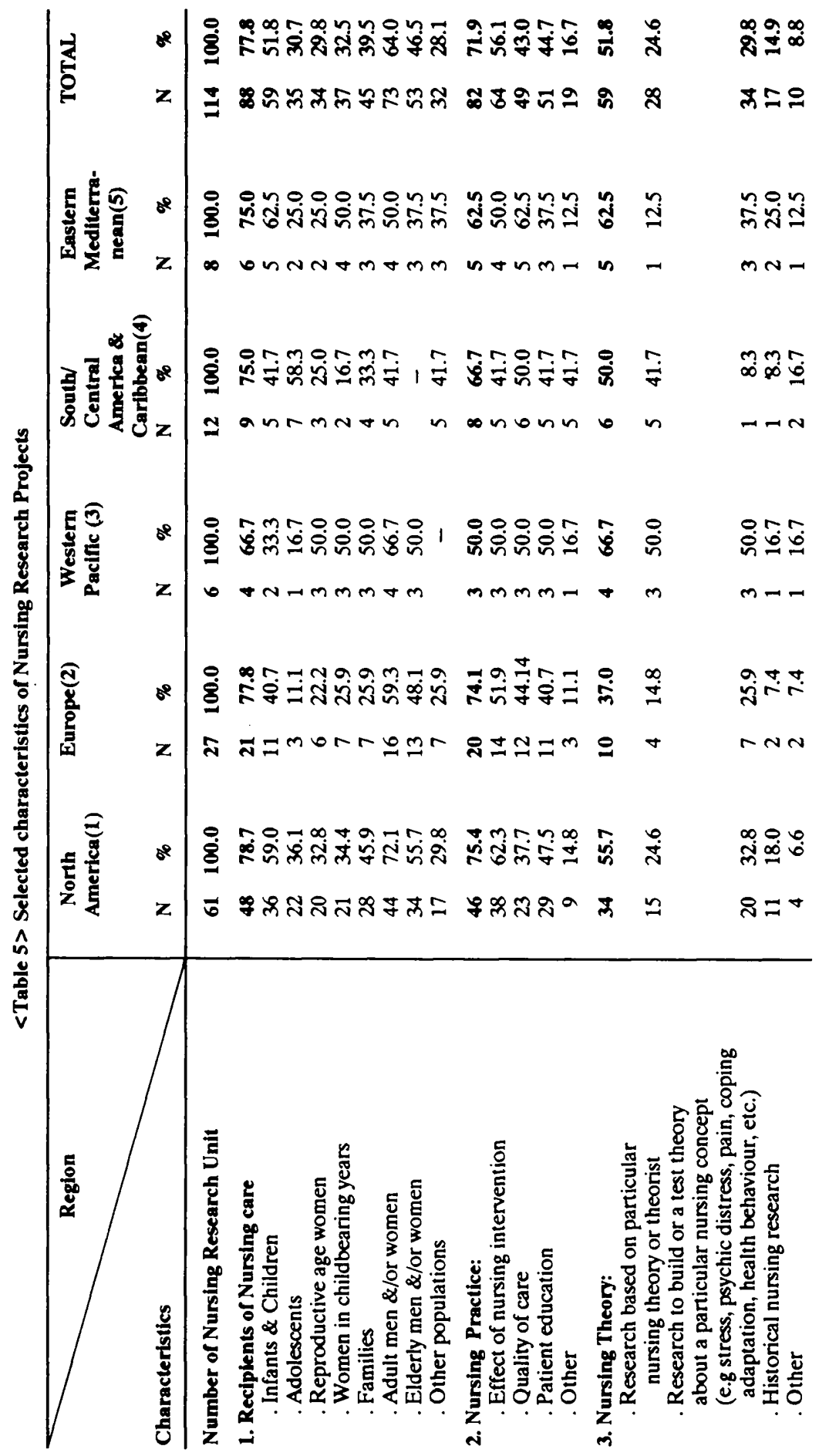




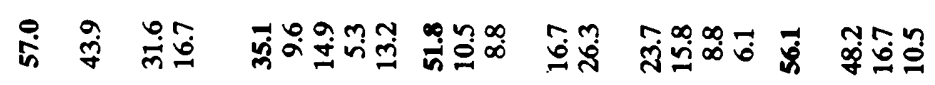

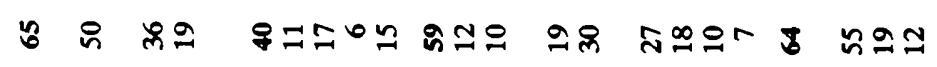

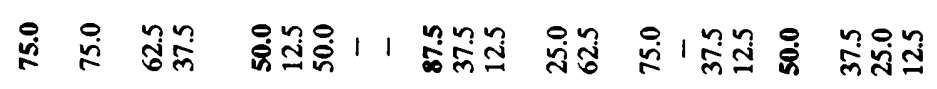

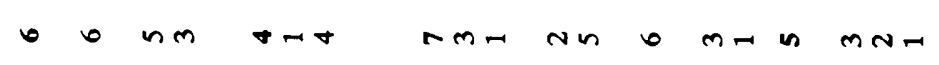

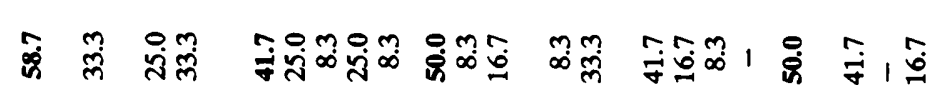

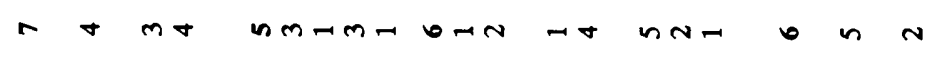

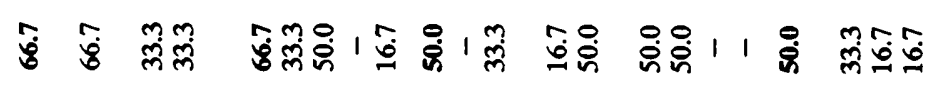

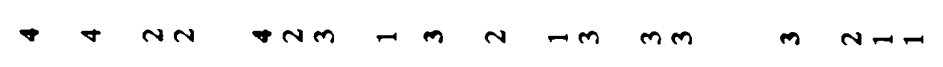

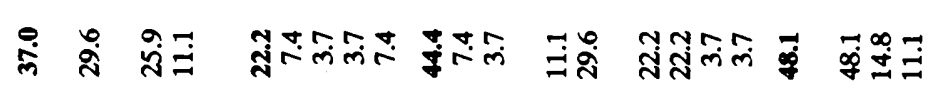

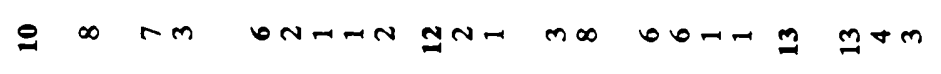

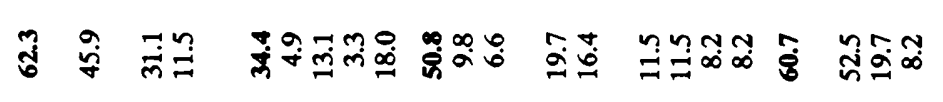

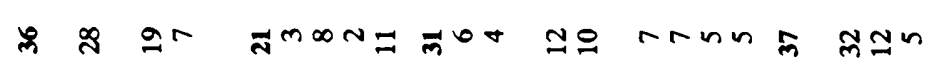

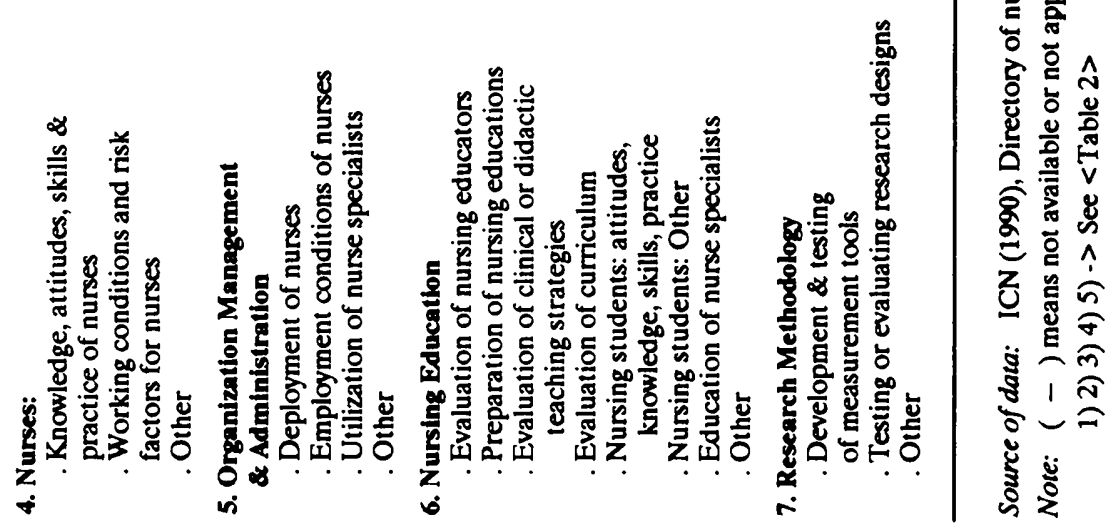




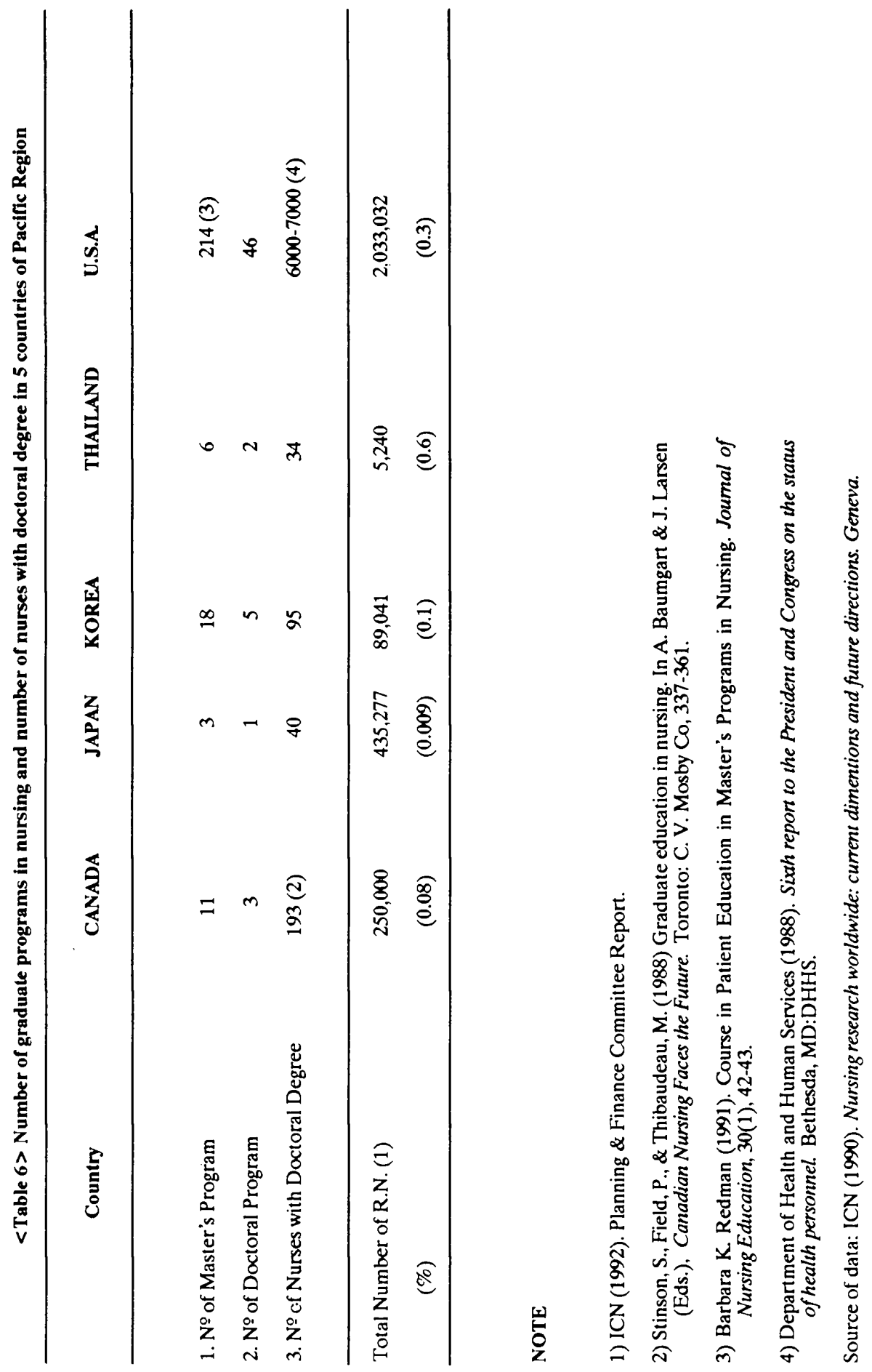




\section{REFERENCES}

AMERICAN NURSES ASSOCIATION. Directions for nursing research: toward the twenty-first century. Kansas, 1985. (pub. $n^{2}$ D-792m).

AMERICAN NURSES FOUNDATION. Setting the agenda for the year 2000. Knowledge development in Nursing. Kansas, 1986.

BARBARA, K. R. Course in patient education in master's programs in nursing. J. Nurs. Educ., v. 30, $\mathrm{n}^{\circledR} 1$, p. 42-3, 1991.

BOONTONG, $T$. The status of nursing research in Thailand. In: TASK FORCE ON INTERNATIONAL NURSING RESEARCH, Geneva, 1990. Nursing research worldwide: current dimensions and future directions. Geneva, International Center for Nursing Research/International Council of Nurses, 1990.

BRINK, P.; WOOD, M. Basics steps in planning nursing research: from question to proposal. 2 ed. North Scituate, MA; Duxbury Press, 1978.

CIANCIARULLO, T. I. Nursing and nursing research in Brazil. In: TASK FORCE ON INTERNATIONAL NURSING RESEARCH, Geneva, 1990. Nursing research worldwide: current dimensions and future directions. Geneva, International Center for Nursing Research/International Council of Nurses, 1990.

DEGNER, L. F. The status of nursing research in Canada.

FILANI, T. O. Research: a tool for improving the quality of nursing. Nigerian J. Nurs. Stud, v. 1, no 1, p. 3-8, 1988.

HAMRIN, E. K. F. Nursing research in Sweden. In: TASK FORCE ON INTERNATIONAL NURSING RESEARCH, Geneva, 1990. Nursing research worldwide: current dimensions and future directions. Geneva, International Center for Nursing Research/International Council of Nurses, 1990.

HIGUCHI, Y. Nursing research in Japan. In: TASK FORCE ON INTERNATIONAL NURSING RESEARCH, Geneva, 1990. Nursing research worldwide: current dimensions and future directions. Geneva, International Center for Nursing Research/International Council of Nurses, 1990.

INTERNATIONAL COUNCIL OF NURSING. Directory of nursing research units. Geneva, 1990.

INTERNATIONAL COUNCIL OF NURSING. Nursing research worldwide: current dimentions and future directions. Geneva, 1990.

INTERNATIONAL COUNCIL OF NURSING. Future direction: Report of the board of directors/staff Workshop. Geneva, 1990.

INTERNATIONAL COUNCIL OF NURSING. The role of health research in the strategy for health for all by the year 2000. Int. Nurs. Rev., v. 37, n 94 , p. 297-8, 1990.

INTERNATIONAL COUNCIL OF NURSING. Planning \& finance committee report. Geneva, 1992.

KERLINGER, F. N. Foundations of behavioral research. 2 ed., New York; Holt, Rinchart \& Winston, 1973.

KIM, E. S. Nursing research in Korea. In: TASK FORCE ON INTERNATINOAL NURSING RESEARCH, Geneva, 1990. Nursing research worldwide: current dimensions and future directions. Geneva, International Center for Nursing Research/International Council of Nurses, 1990.

MELEIS, A. I. International research priorities: a need or a luxury: Ners. Outlook, v. 37, $n^{\circ} 3$, p. 138-42, 1989.

NORBECK, J. S. (1990). Nursing research in the United states of America. In: TASK FORCE ON INTERNATIONAL NURSING RESEARCH, Geneva, 1990. Nursing research worldwide: current dimensions and future directions. Geneva, International Center for Nursing Research/International Council of Nurses, 1990. 
OLADE, R. A. (1990). Nursing research in Nigeria: a survey and assessment. In: TASK FORCE ON INTERNATIONAL NURSING RESEARCH, Geneva, 1990. Nursing research worldwide: current dimensions and future directions. Geneva, International Center for Nursing Research/International Council of Nurses, 1990.

POLIT, D., HUNGLER, D. P. Nursing research: principles and methods. Philadelphia; J. B. Lippincott., 1978.

STINSON, S. M.; LAMB, M.; THIBAUDEAU, M. F. The Canadian Scene. Int. J. Nurs. Stud, v. 27, n², p. 105-22, 1990.

STINSON, S.; FIELD, P., THIBAUDEAU, M. Graduate education in nursing. In: BAUMGART, A.; J. LARSEN (Eds.), Canadian nursing faces the future. Toronto, C. V. Mosby, 1988. p. 337-61.

TIERNEY, A. J. Nursing research in Scotland, United Kingdom. In: TASK FORCE ON INTERNATIONAL NURSING RESEARCH, Geneva, 1990. Nursing research worldwide: current dimensions and future directions. Geneva, International Center for Nursing Research/International Council of Nurses, 1990.

UNITED STATES. Department of Health and Human Services. Sixth report to the President and Congress on the status of health personnel. Bethesda, 1988.

UNITED STATES. Department of Health and Human Services. Public Health Service. National Institutes of health: task force on nursing research: Bethesda, 1989. (NIH oublication $n^{2} 89-487$ ). 